\title{
Quality Assurance of Medicines in Practice
}

\author{
Beverley Glass ${ }^{1}$ and Alison Haywood ${ }^{2}$ \\ ${ }^{1}$ James Cook University, \\ ${ }^{2}$ Griffith University, \\ Australia
}

\section{Introduction}

The quality of medicines in relation to their stability has previously been seen to be entirely the responsibility of scientists within the pharmaceutical industry. Nowadays, however, since pharmacists have an important role to play in the delivery of safe, effective and quality medicines (drug products), they are increasingly being required to make decisions related to the stability of drugs in the day-to-day practice of both hospital and community pharmacy. These decisions range from deciding on whether a liquid dosage form, extemporaneously prepared from a commercial tablet or capsule is stable or whether it is appropriate to repackage a drug product into a dose administration aid (DAA). Pharmacists always consider the stability of the drug concerned and whether it might be preferable to crush a tablet or sprinkle the contents of a capsule over food or mix it in a drink, as is common practice in many nursing homes, when patients are unable to swallow. Pharmacists are also required to consider the implications of the transfer to a non-manufacturer's pack on the stability of a drug product. Despite the widespread use of DAAs, and the common practices of extemporaneous dispensing (compounding) and crushing tablets to be mixed with various liquid media, there is little available data regarding the drug stability following repackaging or alteration, involving compounding liquids or crushing of tablets.

This chapter examines the stability implications of extemporaneously prepared liquids, tablet crushing and repackaging of tablets and capsules into DAAs, by reviewing the literature and highlighting the research undertaken by the authors. Results from their published data have revealed stability concerns with only $7.2 \%$ of oral liquids prepared extemporaneously, primarily due to interactions between the drug and the excipients in the formulation. Further research has also provided evidence on the stability of medicines commonly repacked in DAAs to support pharmacists in making appropriate clinical and operational decisions regarding this repackaging process.

These findings will confirm the importance of knowledge of drug stability for the practising pharmacist, who is involved with modifying or altering drug products, whether repackaging into DAAs, compounding oral liquids or advising on the suitability of crushing tablets. Guidelines on appropriate practice will be provided, in addition to highlighting challenges facing the pharmacist in continuing to deliver safe, effective and quality medicines. 


\section{Dose administration aids}

Populations are increasing in age worldwide as are the number of medicines prescribed, with a number of these patients receiving their medication in DAAs due to the benefits in terms of health outcomes and cost of health care. Despite the widespread use of these devices, there is little available data on the quality implications, based on the stability of these drug products when repackaged into such devices (Walker, 1992; Ware, Holford et al., 1994; Nunney \& Rayner, 2001; Church \& Smith, 2006). Repackaging of a medicine, involving removal from its primary packaging, invalidates the stability guarantee of the manufacturer. In fact, drug manufacturers on the whole, tend to discourage repackaging of medicines and as there is little quality data available to support this process. It is thus the role of the health care team to ensure optimal patient care by making an informed judgment as to the effect on the quality and safety of this repackaging process.

\subsection{Compliance aids}

Compliance aids, also referred to as Multi-Compartment Compliance Aids (MCCAs) or DAAs (Figure 1), are devices which have been developed to assist patients in managing their medicines by arranging individual doses according to their prescribed dose schedule throughout the day.

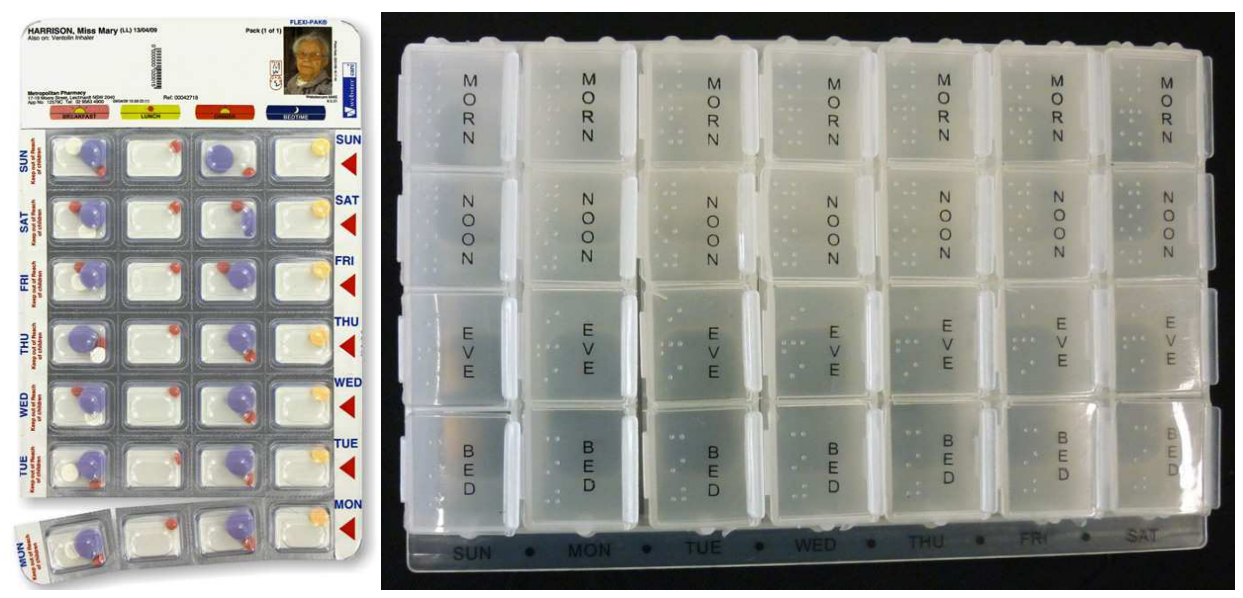

Fig. 1. Examples of Compliance Aids: Webstercare Cold Seal Flexi-Pak® (left), dosette box (right).

These aids have been used to facilitate medication administration to patients for over 30 years and their wider application has been strengthened by various government programs worldwide to facilitate their use (Llewelyn, Mangan et al., 2010). A community pharmacy contractual framework in the UK now places emphasis on assessing and providing practical compliance aids to all patients who fall within the protection of the Disability Discrimination Act 1995 and need help with medicine taking (Chan, Swinden et al., 2007). The Australian Government Department of Health and Ageing has funded a number of professional programs and services under the Better Community Health Initiative of the 4th 
and 5th Community Pharmacy Agreements, including the DAA Program, where the dollar value was increased from nearly $\$ 73$ million to $\$ 132$ million (Australian_Government, 2010). The objective of this program is to identify patients who will derive the most benefit from the supply of a DAA, to develop a sustainable service and payment model capable of meeting the program's aim and to trial the broader use of these aids within the community setting. The provision of a DAA service through community pharmacies is expected to reduce medication related hospitalisation and adverse events through improved medication management. This should result in improved quality of life and health status for patients, and have flow on benefits for the community by reducing the demand on aged care facilities and costs associated with adverse reactions to medication mismanagement.

\subsection{Stability of repackaged medicines}

The stability of a pharmaceutical product may be defined as the capability of a particular medicine, in a specified container, to remain within its physical, chemical, microbiological, therapeutic and toxicological specifications. The shelf-life of a drug product may be affected by the intrinsic stability of the active pharmaceutical ingredient (API) and the excipients, the potential interactions between them, the manufacturing process, the dosage form or drug product, and the packaging and environmental conditions encountered during their transport, storage and use (Aulton, 2007).

Pharmaceuticals are expected to meet specifications for identity, purity, quality and strength throughout their defined storage period. The stability of manufactured medicines is routinely confirmed by the drug manufacturers according to international regulatory requirements $(\mathrm{ICH}, 2003)$, where stability studies on packaged medicines are conducted at real-time long-term and accelerated conditions at specific temperatures and relative humidity $(\mathrm{RH})$. This represents storage conditions experienced in the distribution chain of the climatic zone(s) of the country or region of the world concerned. Manufacturers' packaging is designed to protect drug products from environmental factors encountered during storage, such as light, air (oxygen, carbon dioxide and other gases), and moisture, while limiting interactions between the product and the packaging material. However, this does not guarantee the stability of the API and the drug product on removal and repackaging into a DAA. A recent survey of 392 repackaged products revealed that, although some information regarding the potential stability of solid dosage forms in DAAs can be obtained from manufacturers, there is still a lack of short-term stability data for the transfer of drug products into these devices (Church \& Smith, 2006). Thus, although the benefits of the use of these devices, in terms of both health outcomes and cost of healthcare have been reported (Simmons, Upjohn et al., 2000; Lee, Grace et al., 2006), there is little available data regarding the shelf-life of drug products when repackaged. The fact that there is little available stability data is significant considering the value of these aids, the investment in dollars and the extent to which they are being used to aid adherence.

In electing to repackage a drug product into a DAA, healthcare professionals must consider the implications on drug stability of the transfer to a non-manufacturer pack. Pharmacists thus rely largely on individual drug storage recommendations for the medicine in the manufactures packaging, general guidelines for repackaging, e.g. in Australia (PSA, 2007), the UK (RPSGB, 2003) and USA (USP, 2010), and their basic understanding of inherent drug stability to make case-by-case recommendations as to whether repackaging is appropriate. A 
small number of medicines have been investigated for their stability following repackaging into DAAs, namely aspirin, atenolol, clozapine, frusemide, paracetamol, prochlorperazine, and sodium valproate (Table 1). These studies have contributed significantly to the body of evidence available on repackaging into DAAs and are detailed below. These drug candidates were chosen for study for a number of reasons, including that they were commonly repackaged into DAAs, because of their proven susceptibility to various environmental conditions and/ or because of anecdotal evidence from the practice of problems encountered when these drugs are repackaged either from a patient or health professional perspective.

\begin{tabular}{|l|l|l|}
\hline Active Ingredient & Stability considerations & Literature reference \\
\hline Aspirin & Moisture sensitive & (Haywood, Llewelyn et al., 2011) \\
\hline Atenolol & Light sensitive & (Chan, Swinden et al., 2007) \\
\hline Clozapine & Oxygen sensitive & (Perks, Robertson et al., 2011) \\
\hline Frusemide & Light sensitive & (Bowen, Mangan et al., 2007) \\
\hline Paracetamol & Moisture sensitive & (Haywood, Mangan et al., 2006) \\
\hline Prochlorperazine & Light sensitive & (Glass, Mangan et al., 2009) \\
\hline Sodium valproate & Hygroscopic & (Llewelyn, Mangan et al., 2010) \\
\hline
\end{tabular}

Table 1. Drug candidates investigated for repackaging into DAAs.

\subsection{Repackaging moisture-sensitive medicines}

Three studies (Haywood, Mangan et al., 2006; Llewelyn, Mangan et al., 2010; Haywood, Llewelyn et al., 2011) have reported on the stability considerations of repackaging medicines that are hygroscopic or sensitive to moisture. The medicines were exposed to controlled room temperature conditions and accelerated conditions (elevated temperature and relative humidity). The findings of all studies emphasize the importance of ensuring that these medicines are stored in appropriate well-sealed devices. While well-sealed devices, such as the WebsterPak ${ }^{\circledR}$ are commonly utilised in community and hospital practice, it is not known which devices are used by patients in their homes, since many of these devices that do not have adequate air-tight seals, such as the dosette box (Figure 1), are available in supermarkets and general stores. One of the studies also investigated whether splitting tablets, as is commonly undertaken by patients on low-dose Aspirin, had any adverse effects on the stability and quality of these tablets, when repackaged.

\subsubsection{Paracetamol}

Haywood and colleagues (Haywood, Mangan et al., 2006) examined the stability implications of repackaging commonly used $500 \mathrm{mg}$ paracetamol tablets (Panamax, Sanofi Synthelabo) in a DAA frequently employed in practice (Multidose WebsterPak®). Paracetamol has the potential to undergo hydrolysis and therefore requires protection from moisture. The samples in this study were stored under controlled long-term $\left(25^{\circ} \mathrm{C} ; 60 \% \mathrm{RH}\right)$ and accelerated $\left(40^{\circ} \mathrm{C} ; 75 \% \mathrm{RH}\right)$ conditions as per the $\mathrm{ICH}$ (International Conference on Harmonisation of Technical Requirements for Registration of Pharmaceuticals for Human Use) guidelines for a period of three months. Physical characteristics of the tablets, including weight uniformity, physical appearance, hardness, friability, disintegration and dissolution were evaluated at time $=0$, directly after heat sealing, 1 month and 3 months. Chemical 
stability was confirmed by a validated high performance liquid chromatography (HPLC) method. The results were compared to control samples stored in the original packaging.

The results of the study were very favourable for repackaging paracetamol, indicating that all requirements for the physicochemical stability were met with the paracetamol content within the required British Pharmacopoeial (BP) range of $95-105 \%$ of the labelled amount, for all storage conditions, even those conditions of high humidity. The results suggest that paracetamol tablets repackaged into a DAA offering sufficient protection from moisture would remain stable for a reasonable in-use period of approximately six weeks (i.e. allowing two weeks for advanced packing and delivery on a four-week supply).

\subsubsection{Aspirin}

Aspirin (acetylsalicylic acid) in low-doses has been increasingly prescribed for primary prevention of stroke and acute myocardial infarction in the elderly. A recent study has indicated that low-dose aspirin is also a cost-effective option in primary prevention and the majority of healthcare systems are more than willing to pay for any additional QualityAdjusted Life Years (QALYs) gained (Annemans, Wittrup-Jensen et al., 2010). It is often more cost-effective for patients to purchase standard dose $(300 \mathrm{mg})$ aspirin and to cut the tablet in half to achieve a 'low-dose' equivalent. Tablet splitting or dividing has been an accepted practice for many years as a means of obtaining the prescribed dose of a medication and for cost-saving purposes (Marriott \& Nation, 2002). However, the storage of split tablets is not well discussed in the literature and anecdotal evidence suggests that especially elderly patients or their carers split tablets in advance and then store the split tablets in bottles that previously contained the same medication, a different medication or some other substance, or in a compliance aid such as a dosette box (Marriott \& Nation, 2002). Due to stability concerns, patients and carers are usually advised that when half a tablet is taken, the unused half should be immediately discarded, particularly with medicines that are known to be unstable when exposed to light and air.

Considering the above practices and the fact that acetylsalicylic acid is rapidly hydrolysed to salicylic acid on exposure to moisture, a recent study assessed the stability of $300 \mathrm{mg}$ aspirin tablets (Solprin Dispersible Tablets, Reckitt Benckiser) when repackaged in a dosette box obtained from a local supermarket and stored under a number of in-use conditions, both as a whole and split tablet (Haywood, Llewelyn et al., 2011). This is an important consideration as it is a decision to be made in practice by pharmacists or at home by patients and carers. The acetylsalicylic acid content remained within BP specifications (95-105\% of the labelled amount) for all except the accelerated storage conditions, with $93.4 \%$ of the drug remaining in this case, and the salicylic acid content at $0.04 \%$ (BP limit $0.0006 \%$ ). The split tablets did not display any additional degradation of the acetylsalicylic acid or increased amount of the degradant salicylic acid, when compared to the whole tablets under the same conditions. While the acetylsalicylic acid content remained within specifications under standard room conditions, it must be noted that the limit for the degradant was exceeded under all conditions. Additionally there was some colouration and disintegration of the tablets, thus compromising the quality of this medication and suggesting that this practice of repackaging by patients is inappropriate. This study in fact does confirm the instructions given that these dispersible tablets should not be removed from their original packaging and that if tablets are split, that the remaining half should be discarded. 


\subsubsection{Sodium valproate}

Llewelyn and colleagues (Llewelyn, Mangan et al., 2010) undertook a study on the stability of $100 \mathrm{mg}$ sodium valproate tablets (Epilim, Sanofi-Aventis) repackaged into DAAs (WebsterPak ${ }^{\circledR}$ ) and stored under various temperature and humidity conditions. Sodium valproate, a commonly used antiepileptic is unstable in the presence of moisture due to its hygroscopic and deliquescent nature. The results revealed that while the sodium valproate content in the tablets remained within an acceptable range (90-110\% of the labelled amount) under all storage conditions for eight weeks, the physical stability was not maintained, with unacceptable weight variation in the tablets, changes in their dissolution profiles and significant changes in their appearance, under accelerated conditions, due to the hygroscopicity of the API, even after only three weeks of storage (Figure 2) (Llewelyn, Mangan et al., 2010).

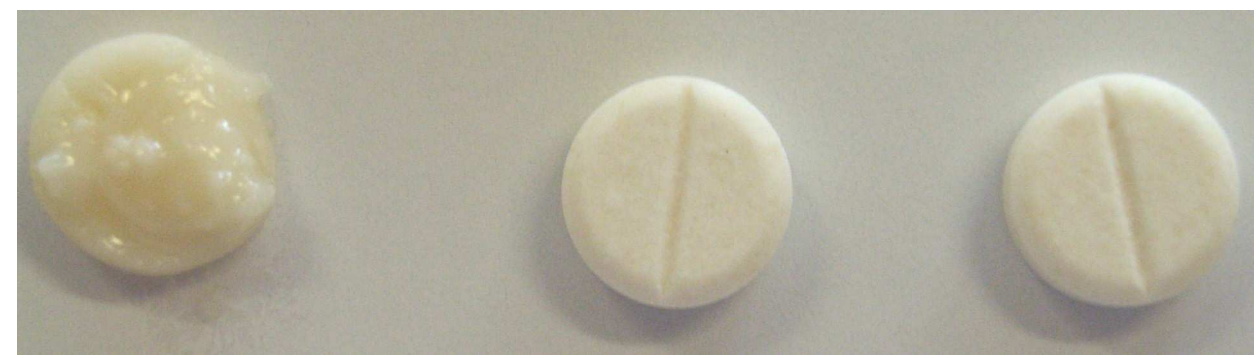

Fig. 2. Sodium valproate tablets after 21 days of storage at accelerated $\left(40^{\circ} \mathrm{C} ; 75 \% \mathrm{RH}\right)(\mathrm{left})$, refrigerated $\left(2-8^{\circ} \mathrm{C}\right)$ (middle) and controlled room temperature $\left(25^{\circ} \mathrm{C}\right)$ (right) conditions.

The results of this study highlight the fact that accelerated conditions of temperature and humidity should be taken into account, and that cognisance is taken from the fact that in different countries, and in fact within the same country, the climatic conditions might vary considerably. Medicines therefore may be appropriately repackaged in, for example, a temperate region such as London, Los Angeles or Sydney, but repackaging that same medicine in tropical or desert regions such as Darwin or Dubai may be inappropriate due to increased temperature, humidity and light conditions. These findings are thus significant because these accelerated conditions are not uncommonly encountered in northern Australia and other tropical regions worldwide.

\subsection{Repackaging light-sensitive medicines}

Three studies (Bowen, Mangan et al., 2007; Chan, Swinden et al., 2007; Glass, Mangan et al., 2009) have reported on the stability considerations of repackaging medicines that are sensitive to light. The medicines were exposed to controlled room temperature conditions $\left(25^{\circ} \mathrm{C} ; 60 \% \mathrm{RH}\right)$ and accelerated conditions $\left(40^{\circ} \mathrm{C} ; 75 \% \mathrm{RH}\right)$ and two of the studies also included those light conditions specified by the ICH (ICH, 1996).

\subsubsection{Atenolol}

Atenolol is reported to be photoreactive when exposed to UVA-UVB radiation with photodegradation increasing with a decrease in the $\mathrm{pH}$ value (Aryal \& Skalko-Basnet, 2008). 
The main photodegradation product at $\mathrm{pH} 7.4$ has been identified as 2-(4-hydroxyphenyl) acetamide (Andrisano, Gotti et al., 1999) (Figure 3).<smiles>CC(C)NCC(O)COc1ccc(CC(N)=O)cc1</smiles><smiles>CC(C)NC/C=C/Oc1ccc(CC(N)=O)cc1</smiles>

Fig. 3. Photodegradation of atenolol

Chan and colleagues (Chan, Swinden et al., 2007) reported on the stability of atenolol 100 mg tablets in a 28-chamber compliance aid with transparent lids, stored for four weeks at room temperature $\left(25^{\circ} \mathrm{C} ; 60 \% \mathrm{RH}\right)$ and accelerated $\left(40^{\circ} \mathrm{C} ; 75 \% \mathrm{RH}\right)$ conditions. Tablets were also stored at room temperature in their original packaging and in Petri dishes. All tablets stored at room temperature conditions passed the necessary physical tests (weight uniformity, physical appearance, hardness, friability, disintegration and dissolution) and demonstrated chemical stability, however the tablets stored at accelerated conditions although chemically stable, showed an increase in disintegration time and decreased dissolution time when compared to the tablets stored in the original blister packaging. A limitation of the study was that only one sampling time point (Week 4) was used with comparison of the results to the tablets stored in the original packaging, as opposed to observing changes from an analytical determination at the outset (time $=0$ ). Further, the brand of the compliance aid or the degree of protection afforded against air, moisture and light is unknown (Glass, Haywood et al., 2009).

\subsubsection{Frusemide}

Frusemide, a light sensitive drug commonly used in the treatment of cardiac failure and hypertension is often repacked into a DAA. A study by Bowen and colleagues (Bowen, Mangan et al., 2007) reported on the in-use stability implications of repackaging $40 \mathrm{mg}$ frusemide tablets (Uremide, Alphapharm). In addition to storing the medicines under controlled room temperature conditions $\left(25^{\circ} \mathrm{C} ; 60 \% \mathrm{RH}\right)$, the DAAs (WebsterPak ${ }^{\circledR}$ ) were stored for eight weeks under conditions that reflected a 'home-environment' where DAAs were stored blister-side up in a bathroom exposed to a standard $60 \mathrm{~W}$ tungsten bulb and indoor indirect daylight/ window- filtered sunlight; and a 'pharmacy-environment' where DAAs were stored blister-side up on a bench top exposed to fluorescent lighting and indoor 
indirect daylight. Photostability studies were also performed according to the ICH guidelines (ICH, 1996). The results confirmed the drug content to be within the BP range of 95-105\% for all storage conditions, including the ICH light conditions. Although the physical stability was confirmed by all tests, including weight uniformity, hardness, friability, disintegration, dissolution, under both controlled and in-use conditions, the exposure to light in the pharmacy and under ICH conditions, even after one week, resulted in a yellow colouration of the tablets. The progressive yellow discolouration (Figure 4) (Bowen, Mangan et al., 2007) of the tablets over an eight week storage period was attributed to exposure to fluorescent lighting, which was not encountered under the "homeconditions'. Although the colour change was noted as having negligible effects on the drug content and other physical parameters, such as dissolution of the tablets, it was considered an unacceptable change, since patients are likely to be concerned about a possible compromise in the quality of the medicine, and this may have an adverse effect on patient acceptance and hence adherence.

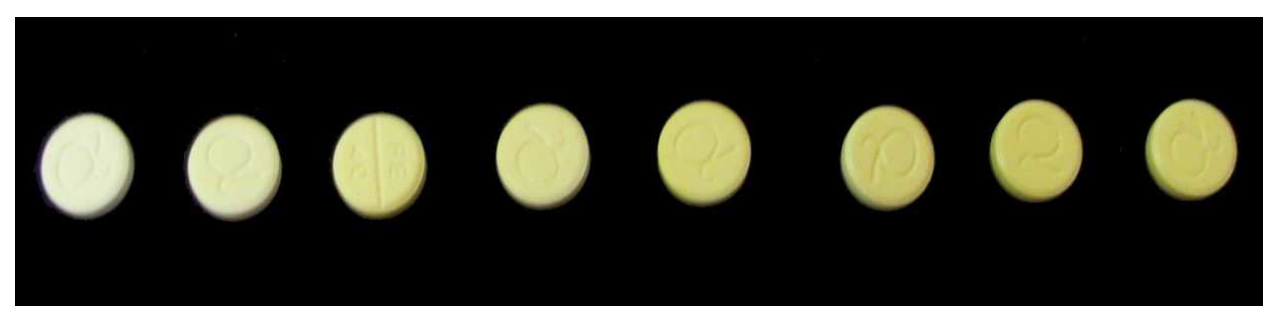

Fig. 4. Progression of colouration of frusemide tablets exposed to fluorescent lighting over an eight week period from left (week 1) to right (week 8)

\subsubsection{Prochlorperazine}

Prochlorperazine, a phenothiazine drug, widely used as an anti-emetic is susceptible to oxidation to the sulphoxide (a metabolite and a photodegradant) under the influence of light (Figure 5). The main metabolites and degradants of all phenothiazines have been found to be inactive at the dopamine receptors (Nejmeh \& Pilpel, 1978; Moore \& Tamat, 1980) and prochlorperazine is reported to cause photosensitivity effects in patients. A study by Glass and colleagues (Glass, Mangan et al., 2009) reported on the physicochemical stability of $5 \mathrm{mg}$ prochlorperazine tablets (Stemetil, Sanofi-Aventis) repackaged into a DAA (WebsterPak $\left.{ }^{\circledR}\right)$. In addition to the controlled room temperature $\left(25^{\circ} \mathrm{C} ; 60 \% \mathrm{RH}\right)$ and accelerated $\left(40^{\circ} \mathrm{C} ; 75 \% \mathrm{RH}\right)$ storage conditions, tablets were also exposed to an in-use condition by placing the repackaged DAAs blister-side up on a bench top exposed to fluorescent lighting and indoor indirect daylight. The results showed chemical and physical stability to be within BP limits (drug content within 95$105 \%)$ however, there were noticeable organoleptic changes in the tablets stored under the in-use conditions, with a progressive grey discolouration over an eight week period, starting in week 2 . The discolouration and the potential for the resulting photodegradants to cause adverse effects in patients suggest that the quality of this medicine had been compromised. 


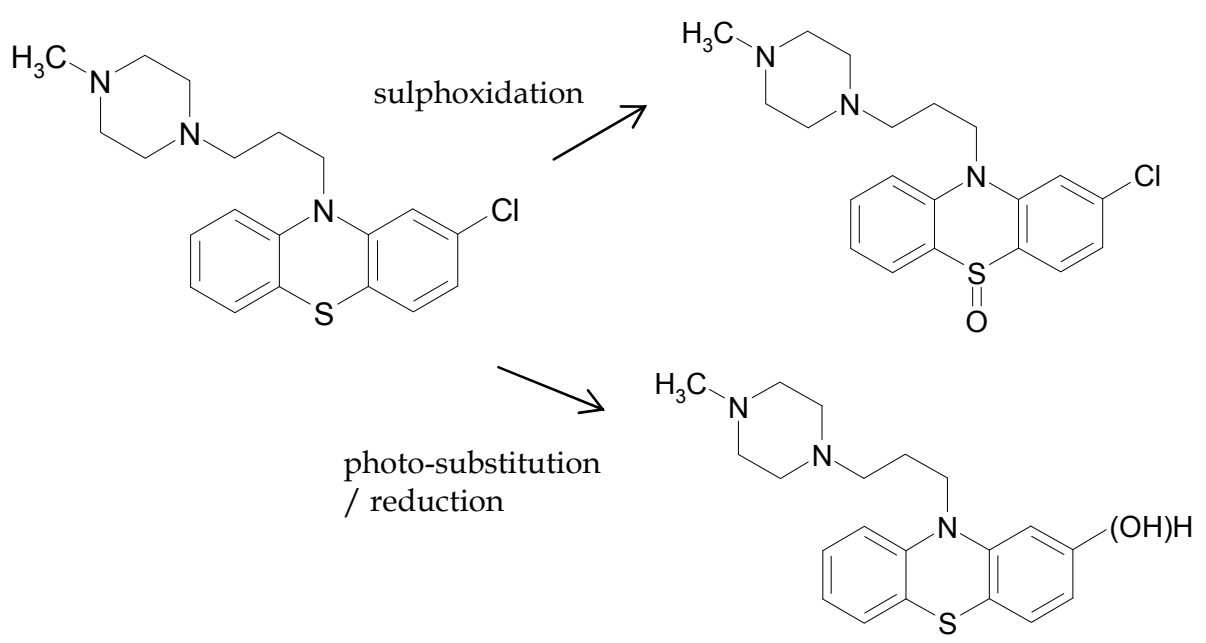

Fig. 5. Photodegradation of prochlorperazine

\subsection{Repackaging medicines sensitive to oxidation}

Only one study (Perks, Robertson et al., 2011) has reported on the stability of repackaging medicines sensitive to oxidation, with preliminary findings suggesting that clozapine undergoes a photo-oxidative process, since the coloration is not apparent during the exposure period in the absence of light.

\subsubsection{Clozapine}

Clozapine is an atypical antipsychotic used in the treatment of schizophrenia. A study by Perks and colleagues (Perks, Robertson et al., 2011) was prompted due to anecdotal reports from hospital pharmacy practice about discolouration of returned clozapine tablets that were repackaged into DAAs, and the known susceptibility of clozapine to oxidation (Kohara, Koyama et al., 2002). The study evaluated both the chemical content and physical stability of clozapine tablets (Clopine, Hospira, and Clozaril, Novartis) repackaged into a DAA (WebsterPak ${ }^{\circledR}$ ) over a six week period. The DAA's were stored under two environmental conditions, namely accelerated conditions $\left(40^{\circ} \mathrm{C} ; 75 \% \mathrm{RH}\right)$, and under a simulated controlled room temperature condition $\left(25^{\circ} \mathrm{C} ; 60 \% \mathrm{RH}\right)$ by placing the DAA with the blister-side facing up on a windowsill in the laboratory, with exposure to both windowfiltered sunlight and fluorescent light. The results were compared to control samples stored in the original packaging under the above conditions. The study also investigated the stability of the tablets exposed to ICH light conditions (ICH, 1996). Although the physical stability, namely weight uniformity, hardness, friability, disintegration and dissolution, was confirmed for all tests at room temperature, under accelerated conditions, the disintegration test did not meet the BP requirements. However, the subsequent dissolution test was successful with $85 \%$ of clozapine dissolving in 45 minutes. The chemical stability was confirmed for all storage conditions, including under ICH conditions (for light), with clozapine content within the BP range of $90-110 \%$. 
Based on the susceptibility to oxidation, and in order to reproduce the colouration noted in the practice of repackaged samples returned by patients, a sample was removed from the original manufacturers packaging and exposed to light and air on the bench beside the simulated controlled room temperature condition samples (Figure 6) (Perks, Robertson et al., 2011). The results for the exposed tablets confirmed the discolouration referred to in the anecdotal reports from practice. These findings show that clozapine, when correctly repackaged, maintained its physical and chemical stability for six weeks. It is therefore assumed that these reports of tablet discoloration were as a result of improper handling of these DAAs by patients. These findings highlight the importance of the role of the pharmacist in providing patient care and advising on the correct handling and storage of their DAAs.

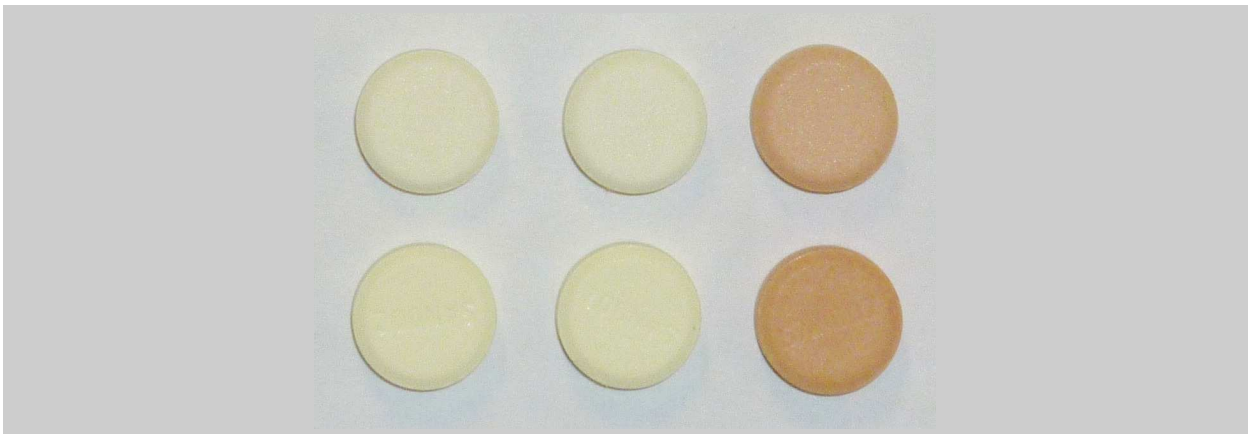

Fig. 6. Photographic comparison of the colour of clozapine tablets from left to right: control sample, sample stored in a DAA under simulated controlled room temperature conditions after 6 weeks, and a sample left out of the DAA packaging on the windowsill after 6 weeks (Clopine ${ }^{\circledR}$ above and Clozaril ${ }^{\circledR}$ below)

\subsection{General guidelines for repackaging medicines}

Various published guidelines, such as the Pharmaceutical Society of Australia (PSA) Professional Practice Standards (PSA, 2010) and Dose Administration Aids Service Guidelines and Standards for Pharmacists (PSA, 2007) have provided general guidance on the suitability of repackaging of solid dosage (tablets and capsules) forms into DAAs and are summarised in Table 2.

A flow chart for the quality management of DAAs in practice is shown in Figure 7 (Haywood, Llewelyn et al., 2011).

The following practical recommendations for ensuring the quality and stability of medicines repackaged into DAAs arising from the above studies include: (i) selecting an appropriate brand of DAA for repackaging medicines that affords appropriate protection against air and moisture; (ii) protecting the DAA containing drugs susceptible to photodegradation from light in the pharmacy and in patients' homes, achieved by either storing the DAA protected from light and/or placing the DAA into a light-protecting sleeve (e.g. foil, cardboard); (iii) careful removal of tablets to prevent accidental rupture of adjacent blisters, thus exposing tablets to air and moisture; (iv) monitoring the DAA integrity during repackaging, dispensing and throughout the in-use period; (v) consideration of an appropriate location to 
store the DAA to avoid unnecessary exposure to light, heat, humidity and away from children, if the device is not child-resistant; (vi) counselling patients on correct use and appropriate storage locations for their DAA; and (vii) following appropriate professional practice guidelines (Haywood, Llewelyn et al., 2011).

Medicines generally unsuitable for packing into DAAs include effervescent, dispersible, buccal and sublingual tablets and significantly hygroscopic preparations.

Medicines administered on an 'as required' basis are generally unsuitable for packing into DAAs, since they may be taken unnecessarily on a regular basis or removed for use at an earlier or later stage, thus exposing the remaining contents to the environment.

Cytotoxic preparations or other medicines posing occupational health and safety risks are generally inappropriate, however the risk-benefit of packing must be considered; for example, packing may be appropriate where non-adherence is considered to be a greater risk.

Only devices that are well sealed and tamper evident should be used.

The length of time taken for the end-to-end packing process should be kept to a minimum; tablets and capsules should be removed from the manufacturer's foil or blister pack immediately before the DAA is packed, and the DAA sealed immediately after it is packed.

Any heat sealing methods should be used quickly and efficiently to minimise exposure of medicines to heat, the likely storage conditions (e.g. exposure to heat, humidity, and moisture) and the length of time the DAA will be in transit.

It is useful to maintain a list of medicines / medicine types that should not be removed from their original pack for repacking in a DAA.

Table 2. Summary of PSA guidelines relating to the suitability of repackaging into DAAs

Choice of an appropriate DAA

1. DAA must be well sealed to protect against air and moisture.

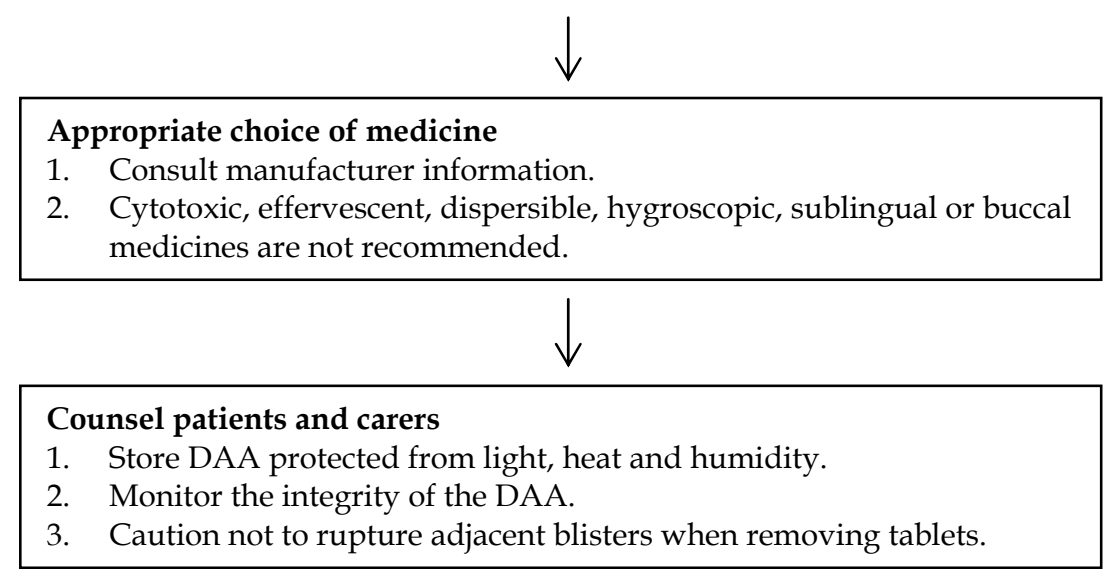

Fig. 7. DAAs - Assuring quality in practice. 


\section{Crushing tablets}

The world's population is ageing and many patients suffer from dysphagia either as a consequence of disease or as part of the ageing process. Elderly patients are more prone to diseases linked to dysphagia, such as Parkinson's and Alzheimer's disease, other dementias, stroke and cancer (Morris, 2005). Further, several age-related changes may contribute to dysphagia, including a decline in salivary gland function resulting in xerostomia, and changes in the sensory function of the aerodigestive tract such as a deterioration of the pharyngo-upper esophageal sphincter (UES) and laryngo-UES contractile reflexes (Kawamura, Easterling et al., 2004). Polypharmacy, involving the use of multiple medicines at the same time, is common among older patients. Dysphagia therefore poses significant challenges for medicine administration, since most adult medicines are available as mainly solid dosage forms (i.e. tablets or capsules).

Tablets and capsules are commonly modified or altered for ease of administration, not only in traditional care settings such as residential aged care facilities and in hospital wards, but also by patients experiencing swallowing difficulties at home. Opening a capsule or crushing a tablet before administration will in most cases render its use to be 'unlicensed'. In addition to the legal implications involved in modifying medicines, there are important safety, stability and bioavailability considerations. Pharmacists thus have a role to play in advising not only on safe medicine use but on any stability issues which may occur on modifying oral solid dosage forms and thus contribute to improving the quality use of medicines in older patients.

\subsection{Medicines that should not be crushed}

There are certain tablets and capsules that should not be modified. The potential risks associated with crushing tablets and opening capsules and the impact on the API is summarised in Table 3 (Haywood \& Glass, 2009). Important considerations include (Haywood \& Glass, 2009):

- Controlled or sustained release medicines are designed to release the active ingredient in a controlled manner over a defined dosing period. Crushing or splitting these drug products will interfere with the release characteristics and usually cause an unintended large bolus dose resulting in toxicity and increased incidence of adverse effects. For example, crushing sustained release verapamil (e.g. Veracaps SR囚) will result in an increased risk of hypotension and bradycardia.

- Enteric coating is used to protect the active ingredient from the acidic environment of the stomach and film coating affords protection from light. Tablets, capsules and capsule contents such as pellets can contain these coatings. For example, nifedipine (e.g. Adalat $\left.{ }^{\circledR}\right)$ is extremely susceptible to light and even brief exposure to ambient light will result in degradation of the API. Omeprazole (e.g. Losec $®$ ) is degraded by exposure to acid and whilst the tablets may be dispersed in yoghurt or orange juice, crushing such tablets will expose the API to acid in the stomach resulting in a loss of activity before the site of absorption in the upper small intestine.

- Delayed release medicines are designed to release the API at a defined site in the gastrointestinal tract. For example, mesalazine (e.g. Mesasal®) is formulated as a resin coated tablet designed to dissolve and release medication in the lower small intestine, where it exerts a local anti-inflammatory effect. 
- $\quad$ Enteric coated tablets, for example Cartia ${ }^{\circledR}$, are designed to minimise the irritant effect of aspirin. If these tablets are crushed, they may be irritant to the oesophagus and the stomach (upper gastrointestinal tract).

- Sugar or film coats are designed to disguise APIs with an unacceptable taste. For example, quinine (e.g. Quinate ${ }^{\circledR}$ ) is coated to disguise the bitter taste. Crushing these tablets, although not altering their effectiveness, may compromise patient adherence.

- There are occupational health and safety (OH\&S) concerns with not only cytotoxic medicines, but also teratogens (e.g. isotretinoin) and those medicines with the potential to cause contact dermatitis (e.g. chlorpromazine). It is important to remember that the clinical indications for the use of some cytotoxics extend beyond the treatment of malignancy, for example, cyclophosphamide (e.g. Cycloblastin $\left.{ }^{\circledR}\right)$ and methotrexate (e.g. Methoblastin $\left.{ }^{\circledR}\right)$ are used to treat some inflammatory disorders. Health care workers and carers need to take appropriate measures to avoid exposure to the powder from these crushed tablets.

\begin{tabular}{|l|l|}
\hline Dosage forms that should not be crushed & Potential risks \\
\hline Extended/ sustained-release product & Increased toxicity/ adverse effects \\
\hline Enteric coat protecting an acid-labile API & Decreased stability/ efficacy \\
\hline Film coat protecting a light-sensitive API & Decreased stability/ efficacy \\
\hline $\begin{array}{l}\text { Delayed-release coat designed to release API at a } \\
\text { defined site in the GIT }\end{array}$ & Decreased efficacy \\
\hline Enteric coat protecting the upper GIT from the API & Increased local irritant effect \\
\hline Sugar/ film coat disguising a poor tasting API & Unacceptable taste/ poor compliance \\
\hline OH\&S of cytotoxic/ teratogenic APIs & $\begin{array}{l}\text { Potential hazards to health care } \\
\text { workers and careres }\end{array}$ \\
\hline
\end{tabular}

Table 3. Risks associated with modifying tablets and capsules

Information on the appropriateness of modifying oral solid dosage forms is available through resources such as the approved product information and the CMI (Consumer Medicine Information) of the medicine. Compiled lists of medicines that should not be crushed or modified are available, such as the Handbook of Drug Administration via Enteral Feeding Tubes (White \& Bradnam, 2007), the Australian Pharmaceutical Advisory Council (APAC) Guidelines for medication management in residential aged care facilities (Appendix F) (APAC, 2002), the Australian Medicines Handbook (AMH) Aged Care Companion (AMH, 2006) and electronic resources such as the list provided by the Institute for Safe Medication Practices (Mitchell, 2011). Many hospitals and aged care facilities have also developed their own lists. These lists, while providing a useful starting point, should not be relied upon as being all inclusive.

\subsection{General guidelines for safe medicine use when modifying medicines}

Pharmacists are able to play an important role in educating patients, carers and other health care professionals concerning the safe and effective administration of medicines. There are reported cases of fatalities that have occurred, not only in traditional care settings, for example where a patient was administered crushed controlled release tablets via a nasogatric tube (Schier, Howland et al., 2003), but also in the patients' home, where a patient 
chewed extended release diltiazem capsules, since they were too large to swallow (Ballard, 1996). This highlights the importance of patient counselling in a community setting, since pharmacists may be unaware of the medication administration techniques and practices adopted by patients at home.

The APAC guidelines for altering medicines (APAC, 2002) provide a six-step process, summarised in Figure 8 (Haywood \& Glass, 2009), to ensure that patients receive the desired therapeutic response from their medicines.

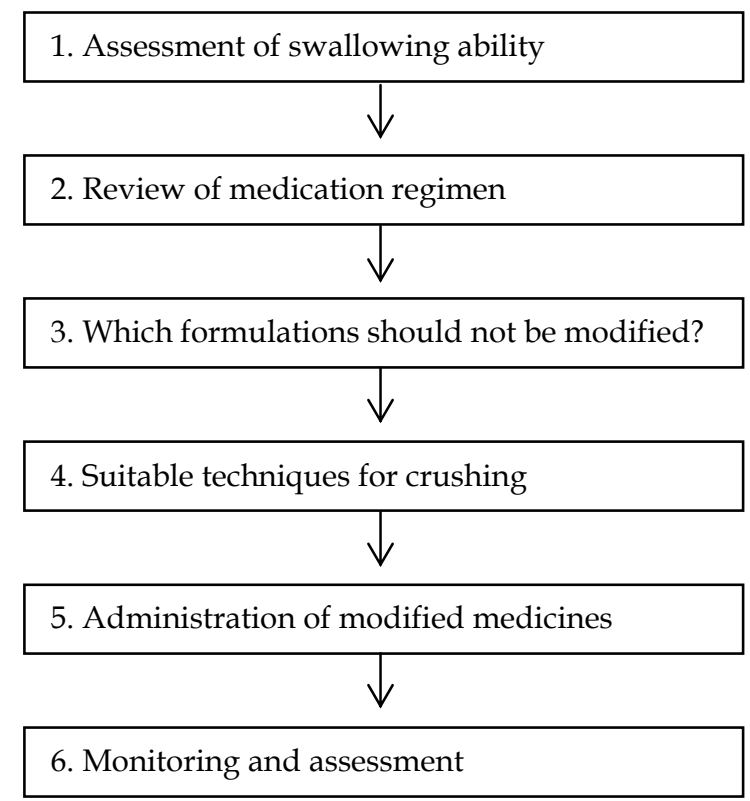

Fig. 8. Six-step process to ensure desired therapeutic response

\subsubsection{Medication management, monitoring and assessment}

There are many important considerations when administering modified medicines, either by the patient themselves at home, or with the assistance of carers or health care professionals in hospitals and aged care facilities.

A patient's swallowing ability should be carefully assessed since their ability to swallow may be a transient disability or may vary during the day. Changing the dosing time and renewed attempts to encourage taking unaltered dosage forms should be the first option, whenever possible. Instinctively, most patients will tip their head backwards when swallowing a tablet, but this actually narrows the oesophagus, making swallowing more difficult. Patients should tilt their head down rather than back as this will widen the oesophagus and may remedy difficulties in taking tablets. The use of liquid 'chasers' or swallowing tablets 'chased' by a few bites of a well chewed banana or soft food (e.g. bread) may be of assistance in some cases. Wherever possible patients should be upright, or as close as practically possible to upright when taking oral medicines. Patients who are unable 
to swallow may be able to take medicines that are not swallowed but are absorbed sublingually (e.g. glyceryl trinitrate tablets) or sucked (e.g. amphotericin lozenges) (Haywood \& Glass, 2009).

Difficulties seen in swallowing oral medicines should provide a stimulus for a medication review. Various options should be considered prior to modifying a medicine, including: changing to a different formulation of the same medicine (e.g. oral liquids/drops, dispersible tablets or transdermal patches); seeking a therapeutic alternative in an appropriate dosage form; or stopping medicines that are no longer necessary. In cases where a different formulation or therapeutic alternative is not available, and a sustained-release product is prescribed, it may be necessary to administer an immediate-release preparation more often, for example immediate release verapamil tablets are usually given three times a day as opposed to once daily administration for the slow-release (SR) preparation, since these preparations can usually be crushed and also more cost-effective. Monitoring and assessing the therapeutic response is especially important when medicines are modified. Adverse effects or lack of expected effects should trigger a review of this practice (Haywood \& Glass, 2009).

\subsubsection{Techniques for crushing tablets}

Appropriate equipment that is non porous and permits complete and reproducible recovery of powdered material should be used, such as a mortar and pestle or appropriate commercially available tablet crusher, to avoid dose inaccuracies. Equipment should be washed and dried between uses to prevent cross contamination. Cytotoxic medicines should have a dedicated set of equipment and special procedures must be adopted to minimise occupational exposure, for example a mortar and pestle enclosed in a transparent plastic bag with the operator wearing a mask and gloves (Haywood \& Glass, 2009). Mixing powdered material with a small amount of food that the patient likes (e.g. jams, fruit purees) is sensible as it disguises unpleasant taste and aids in compliance. The crushed tablets or capsule contents should be given to the patient as soon as possible after crushing and mixing with any food or liquid, as this will minimise both the risk of medication degradation and, in an aged care setting, inadvertent administration to the wrong resident. Crushed tablets or contents of capsules should not be sprinkled onto meals where portions of the meal may be left uneaten, resulting in under dosing. Further practical guidelines to assist in safely modifying medicines are described by Haywood et al (Haywood \& Glass, 2009).

\subsubsection{Counseling and continuing education}

It is important for pharmacists to develop and maintain a current list that is specific to their practice setting and is readily accessible to staff involved in patient counselling or administration of modified medicines. However, with the frequent addition of new medicines to the market and the challenge of maintaining an all-inclusive 'list', it is more important to educate patients, carers, staff and other health care professionals about safe medicine use and to provide them with a background concerning the safety and stability considerations of modifying medicines to ensure the quality use of medicines so that patients receive the best possible therapeutic outcome (Haywood \& Glass, 2009). 


\section{Oral liquids in practice}

The pharmacist, both in community and hospital pharmacy practice, is often challenged with the preparation of a liquid dosage form not available commercially for paediatric patients, those adults unable to swallow tablets or capsules, patients who must receive medications via nasogastric or gastrostomy tubes, and patients who require non-standard doses that are more easily and accurately measured by using a liquid formulation. It is common practice for these liquid dosage forms to be prepared from a commercially available solid dosage form such as a tablet/capsule. Although a number of parameters need to be considered in the formulation of a stable liquid dosage form, there is limited formulation and stability data available (Glass \& Haywood, 2006).

\subsection{Compounding pediatric mixtures}

Children often require titratable individualised doses in milligrams per kilogram of body weight and most children under six years of age cannot swallow tablets (Nahata \& Morosco, 2003). There are a limited number of suitable dosage forms commercially available for children due to the size of the market and resulting lack of financial viability for the pharmaceutical industry of these liquid dosage forms. In addition, there are complexities associated with the formulation of liquid dosage forms due to various physicochemical factors. The preparation of extemporaneous oral liquids, by pharmacists, recently reviewed by Nahata (Nahata \& Allen, 2008) and Giam (Giam \& McLachlan, 2008), therefore provides an appropriate solution to this problem. The following sections provide information on the preparation of safe, stable oral liquids for children and adults in those cases where suitable dosage forms are not available.

\subsection{Physicochemical stability considerations in compounding oral liquids}

Drug stability encompasses chemical, physical, microbiological, therapeutic and toxicological stability not only of the drug substance, but when taking account of the excipients, also the drug product. The extemporaneous preparation of oral liquids can be complex due to the addition of excipients to improve compliance or the stability of the final product. Further, if oral liquids are prepared from a commercially available solid dosage form such as a tablet or capsule, there may be potential interactions between the drug and the excipients (in the commercial product) in the prepared oral liquid. Such interactions may involve the vehicle, preservative, buffering agent, flavouring agent, wetting and suspending agent, viscosity enhancer or even the storage container. However, a review in 2006 of 83 oral liquids extemporaneously prepared by modifying an existing commercial dosage form revealed that only $7.2 \%$ of those compounded oral liquids exhibited stability concerns (Glass \& Haywood, 2006). This review is a useful comprehensive summary of liquid dosage forms prepared from commercially available tablets or capsules and illustrates the low risk associated with these products, if cognisance is taken not only of the API but all those excipients present in the commercial dosage form, used in their preparation.

\subsubsection{Active ingredient and excipients}

In most practice settings, sourcing the API as a powdered raw material is not always practical and thus commercially available tablets and capsules are often used in 
compounding oral liquids. These solid dosage forms however contain many excipients, which although compatible in the solid state have the potential to interact both in solution or suspension, adversely affecting the potency of the API and thus impacting on the shelflife of the compounded oral liquid. There are also certain tablets that should not be crushed and these are detailed in section 3 above. Excipients used in extemporaneous oral liquids commonly include suspending agents or viscosity enhancers, sweeteners and preservatives. They may also contain flavours, colours and buffers. It is not always necessary to colour a product. If a colouring agent is used, it should match the flavour (e.g. red for cherry) and should be used in minimal quantities to produce light-moderate density colours. The Therapeutics Goods Administration (TGA) has a recently updated list of colourings permitted in oral medicines (TGA, 2011). Mixtures may be required to be buffered to an optimum $\mathrm{pH}$, or $\mathrm{pH}$ might need to be taken into account when using certain preservatives (e.g. benzoic acid) which require an acidic $\mathrm{pH}$ to be effective. Commercial liquid vehicles, that contain a combination of sweeteners, flavours, viscosity enhancers or suspending agents and preservatives are available. Some contain non-nutritive sweeteners and are therefore suitable for diabetic patients. Many stability studies are available in the literature that utilise these commercial liquid vehicles, thereby making them a convenient resource, especially since various practice settings may not hold a wide variety of excipients in stock (Haywood \& Glass, 2010).

\subsubsection{Designing an oral liquid formulation}

Pharmacists should be encouraged to use the following process to assist in the compounding of safe, stable oral liquids (Figure 9) (Haywood \& Glass, 2010). In the absence of existing commercially available dosage forms or therapeutic alternatives in a suitable dosage form, a compounded oral liquid is best prepared by searching for a suitable formula. It is important that the stability of these compounded oral liquids is evaluated by methods of analysis that are 'stability-indicating' (Prankerd, 2009). Examples of Journals containing stability-indicating methods of analysis include: Journal of Pharmacy Practice and Research, International Journal of Pharmaceutical Compounding, and the Journal of American Health-System Pharmacists. However, a suitable search engine will provide results from a wider range of journals. For example Medline (http://www.ncbi.nlm.nih.gov/pubmed) and Google scholar (http:// scholar.google.com.au/schhp?hl=en\&tab=ws) are free-access online search engines.

Useful texts include: Allen's Compounded Formulations (Allen, 2003), Paediatric Drug Formulations (Nahata, Pai et al., 2004), Stability of Compounded Formulations (Trissel, 2009), however it is important to check whether there is evidence for the stability of these formulations (Haywood \& Glass, 2010).

Should no suitable formula be available in the literature, pharmacists may be required to design a formula from first principles. Designing an oral liquid, using sound scientific principles, is a lengthy process and would require careful consideration of a number of factors including: potential degradation of the active API by pathways such as oxidation, hydrolysis, photolysis or thermolysis; storage, preservation and packaging considerations and assigning a suitable shelf-life to the formulation; and interactions between excipients and the API, especially if tablets or capsules are used as the source. The manufacturer of the solid dosage form may be able to provide useful stability data for the API. Generally, a commercial liquid vehicle would be the preferred choice, since it would contain all the 
necessary excipients to formulate the oral liquid. It is also preferable to obtain the API in pure powder form as opposed to using a commercial product, since the excipients in the commercial product will add to the complexity of the final product. The final product should be packaged in a light-resistant container (since many colours and flavours are sensitive to light) with a child-resistant cap and be appropriately labelled (Haywood \& Glass, 2010).

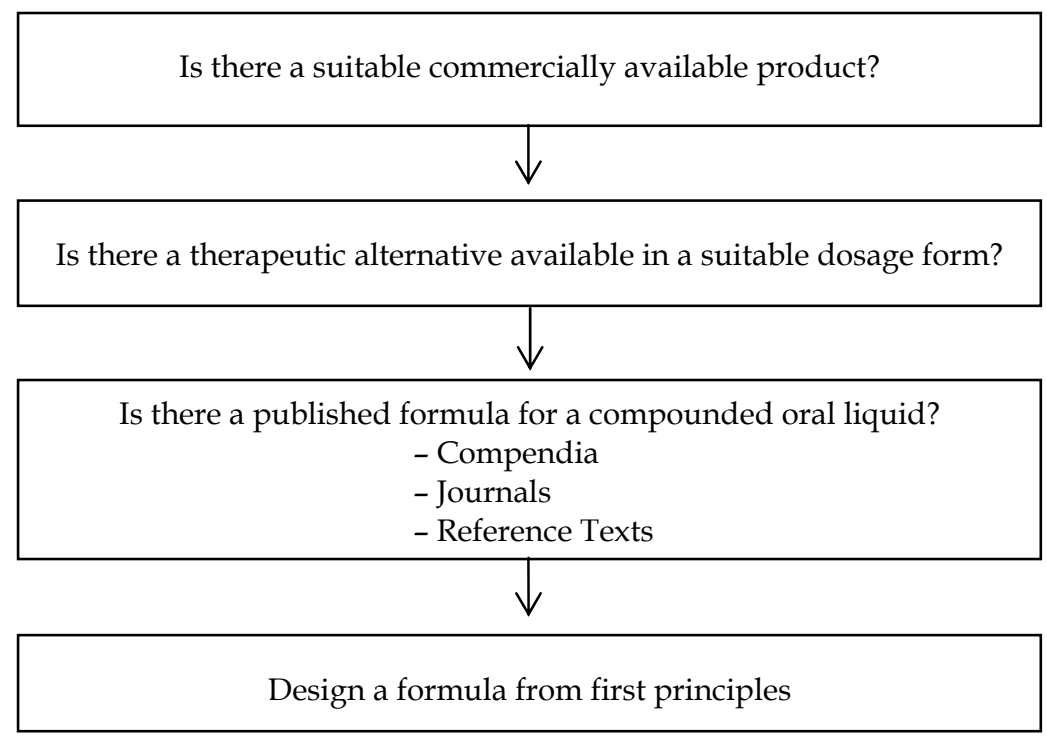

Fig. 9. Compounding safe, stable oral liquids.

\subsubsection{Caution when modifying existing formulae}

Because of the ability of excipients in tablets and capsules to interact with the API in the liquid dosage form, there are problems associated with using stability data for an oral liquid made from powdered raw material and in making the assumption that oral liquids prepared from commercial tablets or capsules will have comparable stability and thus shelf life. This was demonstrated in a study investigating the stability of an isoniazid (INH) liquid prepared using commercially available tablets and a British Pharmaceutical Codex (BPC) formula, where significant degradation of the INH ( $\geq 10 \%$ after 3 days at both 4 and $25^{\circ} \mathrm{C}$ ) was shown whereas the control (using pure INH powder) retained the desired stability of $>$ $90 \%$ after 30 days, as specified in the BPC, under identical conditions (Haywood, Mangan et al., 2005). A replicate control formulation spiked with lactose (an excipient present in the commercial tablets), produced similar degradation profiles to that of the compounded oral liquid. INH is susceptible to hydrolysis and oxidation and is known to interact with reducing sugars (e.g. lactose), to form hydrazines (Figure 10). Although the BPC claimed 28 days stability for the extemporaneously prepared INH mixture, the use of INH powder, as opposed to INH tablets, was specified. This highlights the importance of considering not only the stability of the API but also the potential for interaction with excipients when modifying existing formulae. 


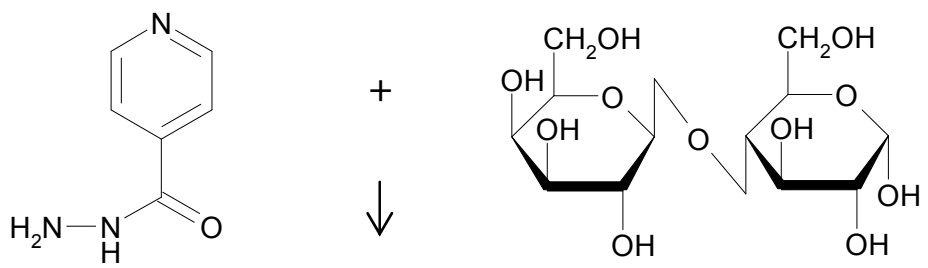

1-isonicotinoyl-2-lactosylhydrazine

Fig. 10. Degradation of isoniazid in the presence of lactose.

The stability of a drug substance in an extemporaneous oral liquid can be compromised by the addition of excipients. When considering the safety and efficacy of oral liquids prepared extemporaneously, it is important to consider not only the stability of the API but the entire formulation. Pharmacists are to be encouraged that by considering various factors such as drug stability, mechanisms and pathways of degradation, potential interactions with excipients in the tablets or capsules, and the availability of formulae (including methods and materials) for stable liquid dosage forms for oral administration in the literature, they are able to confidently dispense an oral liquid dosage form. However, clinical experience, including an assessment of bioavailability whenever possible, with extemporaneous liquid dosage forms for oral administration should be reported in the literature to further support health professionals in this important area of practice.

\section{Repackaging and storage of medicines in developing countries}

Solid dosage forms such as tablets are commonly procured in bulk and repackaged in developing countries in order control costs and therefore to ensure that governments are able to provide medicines to a large majority of the population. This repackaging process involving removal the drug from its primary packaging invalidates the stability guarantee of the manufacturer and often involves the transfer of the tablets to a small 'bank bag' which may be clear, opaque white, yellow, brown or red and manufactured from polyvinylchloride (Figure 11). Although the pharmaceutical industry is required to assure the stability of drugs under certain conditions of temperature light and humidity, these conditions may not be inclusive of in-use conditions. These in-use conditions may relate to accelerated temperature, light and humidity conditions, but may also simply be due to the fact that a request to store a drug product under refrigerated conditions cannot be adhered to in the a developing country, due to the patient simply not having access to a refrigerator.
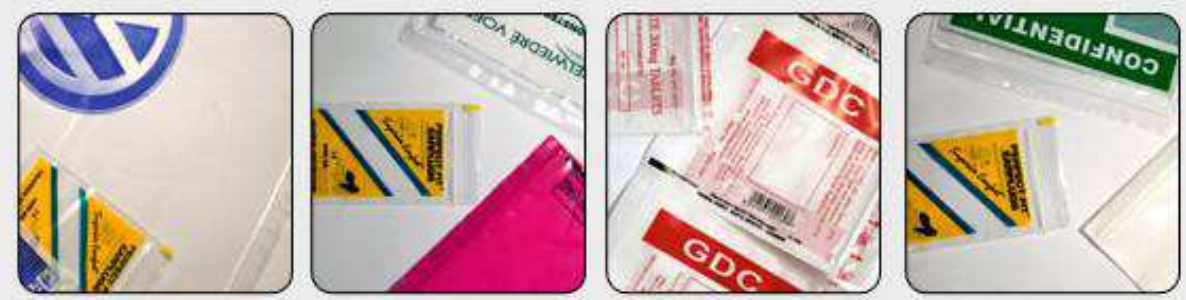

Fig. 11. Examples of Bank Bags (re-sealable polyethylene bags for dispensing tablets) Stripform ${ }^{\circledR}$ Packaging. 


\subsection{In-use stability guidelines}

Although the ICH Guideline on Photostability ( $\mathrm{ICH}, 1996)$, describes a protocol for testing the stability to light of both the drug substance and drug product, it fails to provide a protocol for photostability testing under patient in-use conditions. Since this guideline was published in 1996 and has been implemented in the US, EU and Japan and the Pharmaceutical Industry has experience in these testing procedures, it has been suggested by Baertschi et al (Baertschi, Alsante et al., 2010), that the time has come to revise these guidelines to accommodate in-use conditions. Although the aim of photostability testing is that it should show that exposure to light does not result in an unacceptable change in both the drug substance and the drug product, by excluding any in-use testing the quality of the product to the end consumer, the patient could be compromised. Figure 12 represents a sequential testing which provides some recommendations as to those drug substances and products which are not included in the guideline such as topical agents e.g. creams, transdermal patches and intravenous preparations. There is however no reason why this should not be extended to the repackaging of oral solid dosage forms such as tablets and capsules and apply to all stability testing protocols, including in addition to light, appropriate in-use conditions of temperature and humidity. Lagrange has concurred with the findings by Baertschi et al, in a review on the current perspectives on the repackaging of solid oral dosage forms and stability implications for this process (Lagrange, 2010). Recognising the lack of availability of stability data, they are proposing that factors such as the barrier properties of the packaging materials, the hygroscopicity and light sensitivity of drug molecules and any pre-formulation stability data should be used to generate a list of drugs which should not be repackaged. Because of the advantages associated with the repackaging of drugs into compliance aids, they do recommend that it is the pharmacist who is required to assess the risk of this process.

STEP 1: Is the medicine stable when exposed to light unpacked - if YES to STEP 2

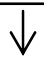

STEP 2: Is the medicine stable when exposed to light in primary pack - if YES to Step 3

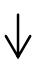

STEP 3: Is the medicine stable when exposed to light in secondary pack - if YES to Step 4

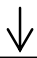

STEP 4: Do not transfer to a less protective pack in community/hopsital pharmacy practice

Fig. 12. Sequential photostability testing protocol

\subsection{Risks and benefits associated with repackaging in developing countries}

The obvious benefits associated with repackaging of medicines in developing countries are that of cost-reduction due to bulk purchases of drug products. However the risks associated with repackaging reported in the literature have to a large extent been centred on issues 
other than drug quality in terms of stability considerations and include (Leon Villar, Iranzo Fernandez et al., 2001; Kelly \& Vaida, 2003): (i) medication errors in the repackaging of medicines; (ii) high cost of repackaging low-quantity prescriptions, which might lead to greater cost due to damage of the packaging by typing directly onto the label; and (iii) expiry dates may be extended beyond what is safe for the patient. Strategies may be implemented in order to avoid repackaging errors, including training pharmacy staff on safety issues, and storage and labelling of drug products in the pharmacy, also referred to as the design of a quality control line. The United States Pharmacopoeia (USP) standards on packaging of drug products, expiry dates and monitoring of temperature conditions have also been revised (Obeke, Bailey et al., 2000).

\subsection{Repackaging of light-sensitive medicines}

Three drug products (tablets) have been evaluated in terms of their stability to light when repackaged in various 'bank bags'. Frusemide and chlorpromazine are known to be light sensitive (Bundgaard, Nørgaard et al., 1988; Chagonda \& Millership, 1989), while pyrazinamide, exhibits good stability and is frequently repackaged into 'bank bags' in developing countries for the treatment of patients with tuberculosis.

\subsubsection{Frusemide and chlorpromazine}

Frusemide tablets placed in a white opaque polyvinyl bag, the original blister (red) packing and in a white opaque securitainer were exposed to window-filtered sunlight under ambient temperature $\left(25-40^{\circ} \mathrm{C}\right)$ conditions for 10 days (Soneman, 1995). Both the appearance of the tablets and the drug content (using a validated HPLC method) was monitored. In all cases discoloration of the tablets, similar to that observed on repackaging of these tablets into a DAA of these tablets was noted. The percentage decrease in the frusemide content was $14.49 \%, 12.73 \%$ and $21.27 \%$ respectively, with further investigation revealing that temperature played a significant role in accelerating the photodegradation of the repackaged frusemide. Recommendations were that patients be counselled on the storage of repackaged frusemide tablets. Chlorpromazine similarly exposed to window filtered sunlight under ambient conditions in a white opaque polyvinyl bag, discolored, with only $76 \%$ of the drug remaining after the exposure period of 1 month (Jacobsen, 1997). For chlorpromazine it was recommended that in addition to counseling on storage of tablets to be protected from light, that tablets would be repackaged bi-monthly.

\subsubsection{Pyrazinamide}

Since pyrazinamide is commonly repackaged into 'bank bags', the effect of exposure to window-filtered sunlight for 3 days in both a 'yellow bag' commonly used in clinical practice and a 'brown bag' was investigated. For both bags tested, photodegradation of pyrazinamide was noted with the extent of degradation dependant both on the time of exposure and the 'type' of bag. Results indicated that pyrazinamide was most stable in the 'brown bag', with $95 \%$ of the drug remaining while in the 'yellow bag' $8 \%$ of the drug degraded. Although the protection offered by the 'brown bag' was superior, its use was limited in practice due to lack of aesthetic appeal and patient acceptance (Defferary, 1993). 


\subsection{Repackaging moisture-sensitive medicines}

Some moisture sensitive drugs, because of their hygroscopicity absorb moisture resulting in tablets becoming unusable, due to loss of physical form. However there are instances where the absorption of moisture by drugs may cause a polymorphic transition and as result altered drug dissolution and bioavailability, which has the potential to seriously compromise the quality of the drug product.

\subsubsection{Carbamazepine}

The antiepileptic drug carbamazepine has the ability to lose its effectiveness when exposed to moisture due to a transformation from the anhydrous form to the dihydrate, which although thermodynamically stable is less soluble and thus less bioavailable (al-Zein, Riad et al., 1999). A study investigated the effect of repackaging of carbamazepine tablets into white opaque 'bank bags' stored under ambient $\left(25^{\circ} \mathrm{C} ; 60 \% \mathrm{RH}\right)$, accelerated $\left(40^{\circ} \mathrm{C} ; 75 \% \mathrm{RH}\right)$ and light (window-filtered sunlight) conditions for 30 days (Maharaj, 1997). Results from this study however confirmed both the chemical and physical stability of the repackaged carbamazepine tablets, under all storage conditions and thus the integrity of the 'bank bag'.

\section{Conclusion}

This chapter highlights that despite the rigor of the requirements for the pharmaceutical industry to provide quality medicines, there are a number of factors which have the ability to contribute to the patient receiving a medicine, which is not of an appropriate quality. This research confirms the role of health professionals especially pharmacists, because of their specialist knowledge in medicines of being able to contribute substantially to ensuring the quality of medicines for patients. It also raises the question as to whether we should be looking more closely at not only undertaking more research independently into in-use drug stability, but adding to the requirements for in-use stability testing to be undertaken on medicines by the pharmaceutical industry.

\section{Acknowledgment}

The authors wish to acknowledge James Cook University, Griffith University and Dr Sherryl Robertson, Mrs Martina Mylrea and Ms Victoria Llewelyn.

\section{References}

al-Zein, H., Riad, L. E. \& Abd-Elbary, A. (1999). Effect of packaging and storage on the stability of carbamazepine tablets. Drug Dev Ind Pharm Vol.25, No.2, pp. 223-227

Allen, L. V. J. (2003). Allen's compounded formulations: the complete US pharmacist collection, Washington DC, American Pharmaceutical Association

AMH (2006). Australian medicines handbook. Drug Choice Companion: Aged Care, 2nd ed, ISBN 9780980579031, Adelaide, Australian Medicines Handbook Pty Ltd

Andrisano, V., Gotti, R., Leoni, A. \& Cavrini, V. (1999). Photodegradation studies on Atenolol by liquid chromatography. Journal of Pharmaceutical and Biomedical Analysis Vol.21, No.4, pp. 851-857 
Annemans, L., Wittrup-Jensen, K. \& Bueno, H. (2010). A review of international pharmacoeconomic models assessing the use of aspirin in primary prevention. Journal of Medical Economics Vol.13, No.3, pp. 418-427

APAC (2002). Australian Pharmaceutical Advisory Council. Guidelines for medication management in residential aged care facilities, $3 r d$ ed, ISBN 0-642-82113-5, Canberra, Commonwealth of Australia

Aryal, S. \& Skalko-Basnet, N. (2008). Stability of amlodipine besylate and atenolol in multicomponent tablets of mono-layer and bi-layer types. Acta Pharmaceutica Vol.58, No.3, pp. 299-308

Aulton, M. E. (2007). Aulton's Pharmaceutics. The Design and Manufacture of Medicines, ISBN 978-0-443-10108-3, Edinburgh, Churchill Livingstone

Australian_Government (2010). The Fifth Community Pharmacy Agreement between the Commonwealth Government and the Pharmacy Guild of Australia. 7 July 2011, Available from

http://www.5cpa.com.au/iwov-

resources/documents/The_Guild/PDFs/Other/Fifth\%20Community\%20Pharmac y\%20Agreement.pdf

Baertschi, S. W., Alsante, K. M. \& Tonnesen, H. H. (2010). A critical assessment of the ICH guideline on photostability testing of new drug substances and products $(\mathrm{Q} 1 \mathrm{~B})$ : Recommendation for revision. Journal of Pharmaceutical Sciences Vol.99, No.7, pp. 2934-2940

Ballard, D. (1996). Reminder of danger from chewing extended-release products. American Journal of Health-System Pharmacy Vol.53, No.16, pp. 1962, 1964

Bowen, L., Mangan, M., Haywood, A. \& Glass, B. D. (2007). Stability of frusemide tablets repackaged in Dose Administration Aids. Journal of Pharmacy Practice and Research Vol.37, No.3, pp. 178-181

Bundgaard, H., Nørgaard, T. \& Nielsen, N. M. (1988). Photodegradation and hydrolysis of furosemide and furosemide esters in aqueous solutions. International Journal of Pharmaceutics Vol.42, No.1, pp. 217-224

Chagonda, L. F. \& Millership, J. S. (1989). The determination of chlorpromazine, related impurities and degradation products in pharmaceutical dosage forms. Journal of Pharmaceutical and Biomedical Analysis Vol.7, No.3, pp. 271-278

Chan, K., Swinden, J. \& Donyai, P. (2007). Pilot study of the short-term physico-chemical stability of atenolol tablets stored in a multi-compartment compliance aid. European Journal of Hospital Pharmacy Science Vol.13, No.3, pp. 60-66

Church, C. \& Smith, J. (2006). How stable are medicines moved from original packs into compliance aids? The Pharmaceutical Journal Vol.276, pp. 75-81

Defferary, L. A. (1993). A stability study of pyrazinamide solid dosage forms. Port Elizabeth, South Africa, University of Port Elizabeth. Honours Thesis (BPharm).

Giam, J. A. \& McLachlan, A. J. (2008). Extemporaneous product use in paediatric patients: A systematic review. International Journal of Pharmacy Practice Vol.16, No.1, pp. 3-10

Glass, B., Mangan, M. \& Haywood, A. (2009). Prochlorperazine tablets repackaged into dose administration aids: can the patient be assured of quality? Journal of Clinical Pharmacy and Therapeutics Vol.34, No.2, pp. 161-169 
Glass, B. D. \& Haywood, A. (2006). Stability considerations in liquid dosage forms extemporaneously prepared from commercially available products. Journal of Pharmacy and Pharmaceutical Sciences Vol.9, No.3, pp. 398-426

Glass, B. D., Haywood, A., Llewelyn, V. \& Mangan, M. (2009). Compliance aids and medicine stability: new evidence of quality assurance. Current Drug Safety Vol.4, No.1, pp. 74-78

Haywood, A. \& Glass, B. D. (2009). Dosage form modification for the elderly. Australian Pharmacist Vol.28, No.11, pp. 960-964

Haywood, A. \& Glass, B. D. (2010). Paediatric mixtures. Australian Pharmacist Vol.29, No.4, pp. 316-330

Haywood, A., Llewelyn, V., Robertson, S., Mylrea, M. \& Glass, B. (2011). Dose administration aids: Pharmacists' role in improving patient care. Australasian Medical Journal Vol.4, No.4, pp. 183-189

Haywood, A., Mangan, M. \& Glass, B. D. (2006). Stability implications of repackaging paracetamol tablets into Dose Administration Aids. Journal of Pharmacy Practice and Research Vol.36, No.1, pp. 21-24

Haywood, A., Mangan, M., Grant, G. \& Glass, B. D. (2005). Extemporaneous Isoniazid mixture: stability implications. Journal of Pharmacy Practice and Research Vol.35, No.3, pp. 181-182

ICH (1996). ICH Harmonised Tripartite Guideline. Stability Testing: Photostability testing of new drug substances and products Q1B: ICH Steering Committee, 7 July 2011, Available from

http://www.ich.org/fileadmin/Public_Web_Site/ICH_Products/Guidelines/Qua lity/Q1B/Step4/Q1B_Guideline.pdf

ICH (2003). ICH Harmonised Tripartite Guideline. Stability Testing of New Drug Substances and Products Q1A(R2): ICH Steering Committee. 7 July 2011, Available from

http://www.ich.org/fileadmin/Public_Web_Site/ICH_Products/Guidelines/Qua lity/Q1A_R2/Step4/Q1A_R2_Guideline.pdf

Jacobsen, L. J. (1997). A study into the effect of packaging on the stability of chlorpromazine tablets. Grahamstown, South Africa, Rhodes University. Honours Thesis (BPharm).

Kawamura, O., Easterling, C., Aslam, M., Rittmann, T., Hofmann, C. \& Shaker, R. (2004). Laryngo-upper esophageal sphincter contractile reflex in humans deteriorates with age. Gastroenterology Vol.127, No.1, pp. 57-64

Kelly, K. \& Vaida, A. J. (2003). Warning! - Repackaged substances may easily be confused. Pharmacy Times Vol.69, No.5, pp. 30-32

Kohara, T., Koyama, T., Fujimura, M., Tanaka, H., Maeda, J., Fujimoto, T., Yamamoto, I. \& Arita, M. (2002). Y-931, a novel atypical antipsychotic drug, is less sensitive to oxidative phenomena. Chemical and Pharmaceutical Bulletin (Tokyo) Vol.50, No.6, pp. 818-821

Lagrange, F. (2010). Current perspectives on the repackaging and stability of solid oral doses. Annales Pharmacetiques Francaises Vol.68, No.6, pp. 332-358

Lee, J. K., Grace, K. A. \& Taylor, A. J. (2006). Effect of a pharmacy care program on medication adherence and persistence, blood pressure, and low-density lipoprotein cholesterol: a randomized controlled trial. The Journal of the American Medical Association Vol.296, No.21, pp. 2563-2571 
Leon Villar, J., Iranzo Fernandez, M. D., Ventura Lopez, M., Najera Perez, M. D. \& Victorio Garcia, L. (2001). Línea de Control de Calidad en el reenvasado de medicamentos. Bases metodológicas. Diseño. Utilidad. Farmacia Hospitalaria Vol.25, No.1, pp. 31-37

Llewelyn, V. K., Mangan, M. F. \& Glass, B. D. (2010). Stability of sodium valproate tablets repackaged into dose administration aids. Journal of Pharmacy and Pharmacology Vol.62, No.7, pp. 838-843

Maharaj, S. (1997). Carbamazepine tablets: An in-use stability evaluation. Grahamstown, South Africa, Rhodes University. Honours Thesis (BPharm).

Marriott, J. L. \& Nation, R. L. (2002). Splitting tablets. Australian Prescriber Vol.25, No.6, pp. 133-135

Mitchell, J. F. (2011). Oral dosage forms that should not be crushed. Institute for Safe Medication Practices, 7 July 2011, Available from www.ismp.org/tools/donotcrush.pdf

Moore, D. E. \& Tamat, S. R. (1980). Photosensitization by drugs: photolysis of some chlorinecontaining drugs. Journal of Pharmacy and Pharmacology Vol.32, No.3, pp. 172-177

Morris, H. (2005). Administering drugs to patients with swallowing difficulties. Nursing Times Vol.101, No.39, pp. 28-30

Nahata, M. C. \& Allen, L. V., Jr. (2008). Extemporaneous drug formulations. Clinical Therapeutics Vol.30, No.11, pp. 2112-2119

Nahata, M. C. \& Morosco, R. S. (2003). Stability of tiagabine in two oral liquid vehicles. American Journal of Health-System Pharmacy Vol.60, No.1, pp. 75-77

Nahata, M. C., Pai, V. B. \& Hipple, T. F. (2004). Pediatric drug formulations. 5th ed., Cincinnati

Nejmeh, M. \& Pilpel, N. (1978). The effect of the photodecomposition of chlorpromazine on lecithin monolayers. Journal of Pharmacy and Pharmacology Vol.30, No.12, pp. 748-753

Nunney, J. M. \& Rayner, D. K. T. (2001). How are multi-compartment compliance aids used in primary care? The Pharmaceutical Journal Vol.267, pp. 784-789

Obeke, C. C., Bailey, L., Medwick, T. \& Grady, L. T. (2000). Revised USP standards for product dating, packaging, and temperature monitoring. American Journal of HealthSystem Pharmacy Vol.57, No.15, pp. 1441-1445

Perks, S., Robertson, S., Haywood, A. \& Glass, B. D. (2011). Clozapine Repackaged into Dose Administration Aids: A Common Practice in Australian Hospitals. International Journal of Pharmacy Practicepp. (in press)

Prankerd, R. J. (2009). Compounded products - Stability studies in Hospital Pharmacy departments. Journal of Pharmacy Practice and Research Vol.39, No.1, pp. 5-7

PSA (2007). Pharmaceutical Society of Australia. Guidelines and standards for pharmacists. Dose Administration Aids Service. 7 July 2011, Available from http:/ / www.psa.org.au/ site.php?id=2065

PSA (2010). Professional Practice Standards. Version 4. Standard 7: Dose Administration Aids Service, Pharmaceutical Society of Australia

RPSGB (2003). Medicines, Ethics, and Practice: A Guide for Pharmacists, Volume 27, ISSN 09554254, London, Royal Pharmaceutical Society of Great Britain

Schier, J. G., Howland, M. A., Hoffman, R. S. \& Nelson, L. S. (2003). Fatality from administration of labetalol and crushed extended-release nifedipine. The Annals of Pharmacotherapy Vol.37, No.10, pp. 1420-1423 
Simmons, D., Upjohn, M. \& Gamble, G. D. (2000). Can medication packaging improve glycemic control and blood pressure in type 2 diabetes? Results from a randomized controlled trial. Diabetes Care Vol.23, No.2, pp. 153-156

Soneman, L. J. (1995). Evaluation of the relative light stability of furosemide when packed in blister packs, securitainers and approved bank bags. Grahamstown, South Africa, Rhodes University. Honours Thesis (BPharm).

TGA (2011). Therapeutic Goods Administration. Colourings Permitted in Medicines for Oral Use. 7 July 2011, Available from http://www.tga.gov.au/industry/cm-colouringsoral-use.htm

Trissel, L. A. (2009). Trissel's Stability of Compounded Formulations. 4th ed, Washington, DC, American Pharmacists Association

USP (2010). US Pharmacopeial Convention Inc. US Pharmacopeia 33 - National formulary 28 $<681>$ Repackaging into single-unit containers and unit-dose containers for nonsterile solid and liquid dosage forms.

Walker, R. (1992). Stability of medicinal products in compliance devices. The Pharmaceutical Journal Vol.25, pp. 124-126

Ware, G. J., Holford, N. H., Davison, J. G. \& Harris, R. G. (1994). Unit-of-issue medicine administration: time and cost-benefits in a geriatric unit. Australian Journal of Hospital Pharmacy Vol.24, No.4, pp. 329-332

White, R. \& Bradnam, V. (2007). Handbook of Drug Administration via Enteral Feeding Tubes, ISBN 978-0-85369-928-6, London, Pharmaceutical Press 


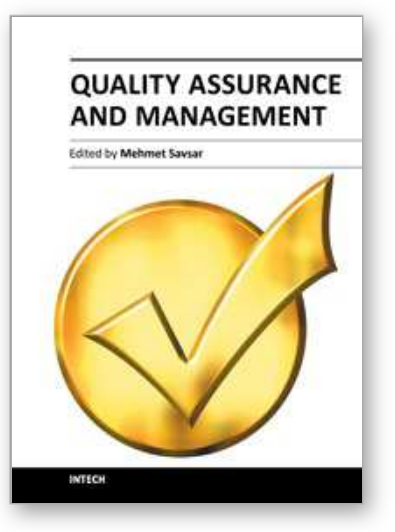

\author{
Quality Assurance and Management \\ Edited by Prof. Mehmet Savsar
}

ISBN 978-953-51-0378-3

Hard cover, 424 pages

Publisher InTech

Published online 23, March, 2012

Published in print edition March, 2012

The purpose of this book is to present new concepts, state-of-the-art techniques and advances in quality related research. Novel ideas and current developments in the field of quality assurance and related topics are presented in different chapters, which are organized according to application areas. Initial chapters present basic ideas and historical perspectives on quality, while subsequent chapters present quality assurance applications in education, healthcare, medicine, software development, service industry, and other technical areas. This book is a valuable contribution to the literature in the field of quality assurance and quality management. The primary target audience for the book includes students, researchers, quality engineers, production and process managers, and professionals who are interested in quality assurance and related areas.

\title{
How to reference
}

In order to correctly reference this scholarly work, feel free to copy and paste the following:

Beverley Glass and Alison Haywood (2012). Quality Assurance of Medicines in Practice, Quality Assurance and Management, Prof. Mehmet Savsar (Ed.), ISBN: 978-953-51-0378-3, InTech, Available from: http://www.intechopen.com/books/quality-assurance-and-management/quality-assurance-of-medicines-inpractice

\section{INTECH}

open science | open minds

\author{
InTech Europe \\ University Campus STeP Ri \\ Slavka Krautzeka 83/A \\ 51000 Rijeka, Croatia \\ Phone: +385 (51) 770447 \\ Fax: +385 (51) 686166 \\ www.intechopen.com
}

\author{
InTech China \\ Unit 405, Office Block, Hotel Equatorial Shanghai \\ No.65, Yan An Road (West), Shanghai, 200040, China \\ 中国上海市延安西路65号上海国际贵都大饭店办公楼 405 单元 \\ Phone: +86-21-62489820 \\ Fax: +86-21-62489821
}


(C) 2012 The Author(s). Licensee IntechOpen. This is an open access article distributed under the terms of the Creative Commons Attribution 3.0 License, which permits unrestricted use, distribution, and reproduction in any medium, provided the original work is properly cited. 